\title{
Sport and Genomics; prospects and ethical framing
}

\section{VAN HILVOORDE ${ }^{1}$}

\section{Introduction}

After the Human Genome Organisation completed the mapping of the human genome, expectations of biotechnology have grown enormously. These expectations not only concern the mapping and sequencing of many organisms, but also the modification of genes to cure diseases or to enhance human features. The impact on sport may vary from preventive screening to the genetic selection of talent and the enhancement of athletic performance with gene doping. To sketch the current state of the art, the following possibilities will be discussed here: the prevention of risks that are related to sports and genetic screening to maximise selection processes in elite sport. I will further discuss some of the empirical and ethical implications of the proposal to impose mandatory DNA testing on professional athletes in more detail. The use of DNA could make it easier to identify and relate other human body material, such as blood and urine, to specific athletes. I will also reflect on the discussion about the most controversial application of gene technology: the enhancement of athletic abilities. Although some of the technologies concerned are still in their infancy, many discussions are framed within strongly opposing positions - extreme optimism and stories of horror occupy the two ends of the spectrum. Finally, I will ask whether or to what extent prospective studies that are conceptualising and framing 'the unknown' might profit from studies and stories with a more narrative and retrospective character.

\section{Excluding the un-fit from sport}

Political and social pressure increases with regard to personal responsibilities for health-related behaviour, in particular when it comes to maintaining a fit body through regular exercise and a healthy lifestyle. ${ }^{2}$ Genomics may empower individuals by providing tools to help them to live up to these expectations. Sport and exercise may indeed be life-saving as well as life threatening. Knowledge about our genetic makeup and its relation to health risks raises various possibilities for prevention of these risks through changes in lifestyle and health behaviour. This knowledge can, on the one hand, contribute to processes of empowerment. However, insight into genetic makeup can, at times, contribute to a restriction of choices.

There is, for example, ample evidence on the risks of brain damage when engaging in contact sports like boxing or soccer. Information on genetic makeup can change the discussion on (compulsory) testing and preventive measures in boxing. There are clear indications that genetic predisposition plays an important role in the prevalence of Parkinson's disease, Alzheimer's disease and 'dementia pugilistica'. In particular, apolipoprotein E $\varepsilon 4$ (APOE $\varepsilon 4)$ is associated with chronic traumatic brain injury in boxing. ${ }^{3}$ Professional boxers who are homozygote for the APOE 44 -gene (seven percent) have a significantly increased risk of getting Parkinson's or Alzheimer's disease at a very young age. Should preventive testing be available and, if so, to whom should it be made accessible? To both adults and children? To both elite and 
amateur athletes? Is paternalistic exclusion of athletes only justified when it concerns young children? Is it justified to present a test as a 'coercive offer', and if so, why? Is it possible to exclude athletes from participating in sport? Are there any reasons why we should not? ${ }^{4}$

Another case is that of 'sudden death' of athletes. Several cases of elite soccer players dying on the pitch have shocked millions of spectators in the past few years (in April 2012, for example, Piermario Marosini collapsed while playing for the Italian club Livorno). This brought home the fact that sport is a risk-fraught activity and drew worldwide attention to the specific role that genetic predisposition could play in predicting such fatalities. ${ }^{5}$ Sudden death (possibly as a result of Hypertrophic Cardiomyopathy) is one of the cases in which the specific role of genes comes to the fore. Proposed prevention strategies include large population pre-participation screening (already common practice in Italy) for all athletes (including in amateur sport) younger than 35 years of age. ${ }^{6}$

Genomics could be used in the future to identify a predisposition to certain risks and to prevent members of the 'at risk' population from engaging in sports. The proposed prevention strategies do however raise important social and ethical questions. Is routine testing, even for healthy athletes, desirable? How carefully are the tests being prepared and introduced? Can coercive tests and the exclusion of athletes on the basis of such tests be justified? If so, on what conditions?

\section{Genetic identification of talent}

One could perhaps argue that, in order to become an elite athlete you first of all have to carefully select the genes of your parents. This is an absurd illustration of the extreme logic of selectivity within modern elite sport. Would it be as absurd to say that in order to become the best athlete, you have to carefully select your gene therapist? This last statement is less absurd, although quite optimistic about the possibilities of gene technology. The identification of genetic makeup that indicates a specific risk might also be helpful for the identification of a favourable genetic blueprint with respect to athletic features. ${ }^{7,8}$ The angiotensin-converting enzyme (ACE), for example, is related to general physical performance, ${ }^{9}$ but is also associated with myocardial infarction. Potential candidate genes were found in elite Australian rowers (in the so-called rennin-angiotensin pathway), which plays a crucial role in cardiac and vascular physiology. These rowers had an excess of the ACE I allele and the ACE II genotype. This excess could be associated with athletic excellence and possibly with a healthier cardiovascular system. The identification of such genetic predispositions may also be used for nutrigenomics and the manufacturing of 'functional foods' in sport.

Genes that influence the production of erythropoietin (EPO), which stimulates the bone marrow to produce more red blood cells, enhancing the blood's capacity to carry oxygen, have also been identified. Another example is a mutation in the myostatin gene that has been associated with muscle hypertrophy in a child ${ }^{10}$. Inhibition of the 
myostatin gene in mice has been shown to lead to a spectacular increase in skeletal muscle mass and strength.

Genetic screening with the purpose of selecting children whose genetic makeup is particularly suited for performing in a certain sport would be one selective tool that also allows the opportunity to advance the moment of selection and to enhance the efficiency of scouting. When children are genetically screened with the aim of identifying certain features of athletic talent, the ethical and pedagogical discussion concentrates on concepts such as 'athletic predestination' and the right to an 'open future'. ${ }^{11}$

The interests of the child need to be carefully weighed against those of ambitious parents, coaches and countries. Knowledge about genetic makeup could, on the other hand, enhance autonomy and contribute to the prevention of harm. A parent's decision to exploit the athletic talent of a child without insight into a 'genetic makeup' is potentially a more restricting decision (given the relative uncertainty about the talent) than a decision that is based upon a genetic profile. This practice of early selection does, however, raise ethical and pedagogical questions about the autonomy of selected children. A child's knowledge that he or she has genetic variants associated with a higher probability of success in sports may be a source of problems. People may have to balance the right to know with the right not to know.

\section{Mandatory DNA testing}

Following a major doping scandal in 2006 (Operación Puerto) when bags of manipulated blood of elite athletes were found, cycling authorities proposed that professional cyclists be subjected to mandatory DNA testing. Jacques Rogge, president of the IOC, commented on the possibilities of creating a DNA database to collect genetic information from all elite athletes. 'Today, the riders have to give urine and blood samples. Tomorrow, this has to include DNA also. It's not very painful: a pin prick inside the cheek, a bit of hair... that's less painful than blood extraction. The data would be well-stored and protected. Tell me, what's the problem? ${ }^{12}$ The AIGCP, the international association of professional cycling teams agreed to the use of DNA testing. In 2007, most professional cycling teams asked their riders to submit their DNA for testing and authorised the International Cycling Union to collect the DNA samples and made riders sign a commitment.

Besides practical problems, this proposal also raised ethical issues, such as the danger of violating privacy, the difficulties of protecting DNA from being used for other purposes, the criminalisation of athletes, and problems relating to consent and autonomy. ${ }^{13,14}$ Privacy, understood as physical privacy, concerns the access to persons and personal spaces. ${ }^{15}$ Over the past few decades, the distinction between athletic and private life has almost disappeared. Not only in cycling, but in many sports the antidoping authorities claim the right to know where the athlete is. Subjecting his or her personal life to scrutiny has become part of the role of an elite athlete and has become an important tool for the enhancement of credibility of athletic performance. 
With regard to informational privacy (access to personal information), the discussion concentrated on questions relating to the storage and protection of DNA. How and under what conditions will the DNA be stored? How do authorities deal with questions regarding consent? The use of DNA testing in sport is not meant for other purposes than to relate blood and urine to specific athletes. But still, there are unknown applications and unspecified uses of the DNA in future cases.

The third type of privacy (decisional privacy) has to do with interference with personal choices. Some riders called the UCI 'dictatorial' because it didn't consult cyclists themselves about this decision. Athletes were forced to 'consent' without knowing exactly how their DNA might be used in the future. A so-called informed consent by the cycling teams was in fact a coercive offer. The words of Patrick Lefèvere, President of AIGCP illustrate this: 'We cannot force the riders to agree to our request, but who refuses will have to assume the consequences. For example, a team could decide not to renew their contract. ${ }^{16}$

Some of the elite cyclists responded to the proposal by arguing that they didn't want to be treated as a criminal. Indeed, one of the arguments against DNA testing was that riders were being criminalised. Mandatory DNA testing is more usually used in the investigation of criminal acts such as murder, rape, incest or kidnapping. It is however doubtful if the term criminalisation offers a valid argument in itself to oppose the proposal. The term criminalisation is problematic in a similar way when using terms such as geneticalisation or medicalisation. It is not always clear whether these concepts are used in a descriptive or normative sense. Many riders themselves use the term crimimalisation in an evaluative way; they regard this development as bad in itself.

Athletes, even when they break a rule, are no criminals and are not meant to be treated as such. The authorities and officials who agree with the proposal use the term, however, in a quite opposite way, namely prescriptive: athletes breaking the doping rule should be criminalised. It is easier to agree upon the descriptive meaning of the term: criminalisation, the process by which behaviours and individuals are transformed into crime and criminals, is something that happens in elite sport, when doping is considered a criminal offence.

If doping is considered a criminal offence, one could argue that riders themselves criminalise the sport, by offending the doping rule. The rule of the game is being legalised, and the offence criminalised. This is not necessarily problematic.

Adherence to the rules is an essential part of sport. Criminalisation of a sporting rule can however be problematic in cases where the means to enforce the rule are not in balance with the offence itself. Violating human (privacy) rights in order to control whether athletes adhere to the rule, as if breaching it should be regarded as a severe criminal act, can become quite problematic. ${ }^{17}$ The efforts to maintain the credibility of the sport may conflict with the human rights of the individual athletes. Proposals such as mandatory DNA testing are intended to create transparency and credibility, but 
may instead lead to greater suspicion and a situation in which athletes are 'guilty until proven innocent'.

These cases of prevention, selection and mandatory DNA testing raise serious questions about the ethical and social implications. They do not seem to be based just upon unrealistic and unempirical speculation. The idea of genetically enhancing human capacities with the aim of improving athletic performance seems to be much more frightening to many people than the previously mentioned cases. Gene doping is an application of gene technology, surrounded by a remarkable variety of both utopian and dystopian scenarios. After explaining some of the technology itself, I will discuss some of these scenarios and, in conclusion, will draw a comparison with the hopes and fears that surrounded the popularisation of the bicycle more than a century ago.

\section{Genetic enhancement}

One can think of several biotechnological applications to enhance athletic performance. Genetic information might be used, for example, to fine-tune training and nutrition in relation to the individual athlete's genetic makeup (accepted by the IOC as a legal application). One of the uses that appeals most to the imagination is the prospect of gene doping (or: somatic genetic modification) in elite sport. Gene or cell doping is usually defined as 'the non-therapeutic use of genes, genetic elements and/or cells that have the capacity to enhance athletic performance. ${ }^{18}$

The insertion of artificial genes is already possible, although there still remains the unsolved problem of controlling the activity of the artificial genes so they don't produce too little or too much of the required substance. There are three possible ways to insert the artificial gene into the patient. The simplest way is to inject the DNA directly into the muscles. Some of the muscle fibres will then take up the DNA. Alternatively, one could introduce the DNA into cells in the laboratory and then inject these modified cells back into the body. Finally, one can utilise viruses for introducing foreign DNA into human cells. Two possible applications of enhancing performance in sport could be the increase of red blood cells by inserting an EPO gene (Erythropoietin is a hormone that stimulates production of oxygen-carrying red blood cells) or the building of muscle mass by inactivating the myostatin gene (this has been successfully carried out in mice). After being injected with a synthetic gene (IGF-1, Insuline-like Growth Factor-1), the muscle force of so-called Schwarzenegger-mice was increased by 60 per cent after a month. The injection of EPO-genes in monkeys made the volume percentage of red blood cells (hematocrit) rise from 40 to 70 (50 is a 'health-limit' within elite sports).

Some researchers think that as soon as gene therapy becomes a well-established technique, gene doping or genetic engineering of elite athletes will also become a routine practice, and there is some evidence to feed this speculation. In 2006, after the German coach Thomas Springstein was charged with administering performanceenhancing drugs to minors, emails were discovered that seemed to show that he was trying to obtain the gene therapeutic (and still experimental) medicine Repoxygen (the so-called 'EPO-gene'). Media worldwide wrote about this evidence that gene doping 
was about to be introduced within elite sport. ${ }^{19}$ For the first time the use of gene doping appeared to be real instead of mere speculation.

It seems that the application of biotechnology in elite sport raises some new and rather complex issues. A major problem concerns the (ethical and practical) implications of control and detection. Anti-doping authorities are facing serious problems in their search for a useful test to identify gene-doped athletes. The protein produced by the artificial gene will be identical to the endogenous protein produced by the human body itself. If pure DNA or cells are used, this DNA will only be present at the site of injection. That means that a muscle biopsy of the injected site would be required. But what if athletes do not consent to a biopsy of muscle tissue in order to control for the 'naturalness' of the DNA? What is considered an autonomous decision within a clinical context could lead to allegations of fraud, in the context of elite sport.

Another complex issue concerns the distinction between therapy and non-therapy. It is very hard to draw a clear line between a therapeutic and an enhancing use of genetics. Why is it that, in contrast to the ill patient that wants to become better, the healthy athlete that wants to get 'better' is target of condemnation? Is there really a difference in principle between gene-therapy to replace defective genes with healthy genes and the enhancement of healthy genes? Although the boundary between therapy and enhancement is often hard to draw, it is still one of the most important criteria of international policy on sport and doping.

\section{Different scenarios}

Most gene therapists will be inclined to temper high expectations and think it is rather unlikely that in the near future the fiction of the genetically modified athlete will become a reality. Many genes are involved in athletic performance, especially in those sports that do not just measure force or speed. There are complex interactions between various genes, as well as between genes and the environment. There is not a single crucial gene for sporting talent which can be identified, inserted or modified at will. On the other hand, gene doping does not seem to be just 'science fiction' anymore. How do we deal with these uncertainties and how can we frame credible scenarios for ethical discussion? One position within the debate starts from the presumption that genetic enhancement will become a safe and broadly accepted procedure. From there, one can reflect on the impact on athletic performance, on sport or on the human being in general. This kind of reflection is popular among the so-called transhumanists, who in general embrace all new technology and optimistically defend the use of technology to extend all human abilities. The use of new technology (including genetic enhancement) is promoted, because it is believed to improve humankind. ${ }^{20} \mathrm{~A}$ transhumanist would ask, for example, why, if some people are born two and a half meters long or with 3 legs, why not make people to fit these descriptions? What's wrong with such procedures if it results in better performance in sports?

Transhumanists and enhancement bioethicists tend to endorse a rather mechanistic and deterministic perspective. Like previous futurists, they have "grounded their work on two simplistic and fallacious assumptions. First, they assume a mechanistic view 
of the individual as a machine whose elements can be easily manipulated. Second, they apply a similarly mechanistic view to human society whose individual elements are fungible individuals to be simply modified or discarded in favor of the whole". ${ }^{21,22}$

Transhumanist philosophy is often accompanied by a version of genetic reductionism ${ }^{23}$ which assumes that athletic performance is primarily determined by the athlete's personal genetic make-up. Having a talent is simply a matter of having the appropriate genes. Enhancing the 'sport genes', then, would obviously enhance athletic performance. The crucial question remains whether what works in the laboratory will also work outside it (extrapolation). Will enhancing specific human capacities lead to the 'enhancement' of an individual or of human beings in general. Even the effects of genetically enhancing parts of the human body (a specific muscle for example) on other parts (like tendons and ligaments) are still largely unknown.

Arguing from a transhumanist position, it does not really matter in what context genetic enhancements are being applied. Take for example the concept of morphological freedom, or bodily autonomy. According to Sandberg ${ }^{24}$ the freedom to modify one's body is not only essential to transhumanism, but also to any future democratic society. In modern liberal democracies people are already relatively free to experiment with their own body. It has, for example, become an accepted phenomenon to adapt a morphological identity to a specific psychological experience of gender identity. One could argue that there is not much difference between a transsexual, someone who voluntarily changes their gender identity, and a voluntary change of specific talents. For a transhumanist there is no sharp moral boundary between a transgender surgery and an 'athletic therapy' that originates in the psychological experience of being born in a body with too little talent for sports.

It is tempting to go along with the arguments in favour of enhancement, if the technique appears to be safe. If the technology is safe, and if it makes us better and happier human beings, will it be acceptable? Yes, of course, why not? There is, however, no convincing argument why absolute morphological freedom would make sport better than it is. It is arguing in consequentialist terms, without exactly knowing the consequences. The 'athletic enhancer' is represented as an autonomous and knowledgeable athlete who a certain point makes a decision: to cheat or not to cheat. However, the decision to genetically modify or not is not simply a matter of cheating or not. Neither is it just a matter of an informed person making use of his or her 'morphological freedom'. It involves a complex weighing not only of individual values (better performance) against communitarian values (the so-called internal goods of sport), but also of the risks, advantages and uncertainties.

For the context of sport, it remains of importance if athletes are still playing the same game. We don't want the gene therapist to become responsible for the outcome of the game. What is lacking within the philosophy of transhumanism is a clear concept of good sporting practice. Elite sport might be more or less equalised with the enhancement of human performances, but little thought has been given, for example, to the internal and social goods of a sporting community. Are athletes still playing the 
same game when gene technology decides the outcome? What does it mean for the concept of equal opportunities and an equal distribution of means for playing the game? The introduction of gene technology may result in inequalities that may be considered irrelevant for the inequalities that the game is supposed to produce and measure. ${ }^{25}$

Starting with a reflection on the question of which features are characteristic of (good) sport, one can further examine the challenges and dangers of new genomic technology. What could be the impact on sport as a social practice, with the rules and values that attach to it? In this case there is indeed a difference between transgender surgery and the choice to genetically enhance your body to become a successful athlete. The first is likely to increase an individual's happiness, without affecting the happiness of other people. The second has a much more direct effect upon other practitioners. That is why most athletes are willing to give up their privacy in order to make detection as fair as possible (which is not to say that the current anti-doping policy is necessarily increasing fairness and justice in sport).

In order to make these uncertainties and conflicting values visible and understandable, it is necessary to ignore deterministic, instrumentalist and overly optimistic perceptions of technology. One of the difficulties is finding language and concepts in which to frame uncertainties and learning processes, without reverting to a conservative position in which all technology is defined as potentially dangerous to the internal goods of sport. The vocabulary of Science and Technology Studies (STS) can be helpful to frame debates on technological innovations that incorporate the intrinsic uncertainties involved, instead of reverting to utopian and dystopian scenarios. While rejecting a deterministic perception of technology, STS studies focus on interaction, dialogue, participation and the use of narratives for anticipatory governance. Boerwinkel, Swierstra and Waarlo ${ }^{26}$ illustrate how narratives and future scenarios can be used as a teaching method to enhance imaginative power, to stimulate thinking ahead and to reflect critically on issues arising from new technology. Arguing from the perspective of the co-evolution of science, technology and society, the authors illustrate how the use of stories that describe possible futures make students aware of conflicting values and their possible role in future developments, Students can then be invited to discuss conflicting moral values and political choices.

In daily discourse we tend to simplify the relation between genetic makeup and human characteristics. This simplification often results in a kind of optimism and hype that, in the case of sport, has been fuelled in the past decade by a list of potential 'gene enhancers'. Experimental gene therapeutic procedures can be seen as magic buttons able to modify features like strength, oxygen, blood or pain. The EPO gene promises to be effective, and could enable the equalising of one relevant athletic characteristic, namely the amount of oxygen in the blood.

If all athletes could insert a similar gene, with similar effects, it is certainly worthwhile to analyse a scenario in which athletes no longer need to be followed and 
criminalised for trying to enhance their red blood cell levels. If athletes have equal levels of oxygen in their blood, other relevant inequalities, like dedication, become more important. It is tempting to focus on examples like this, but most examples of gene therapy will not be that simple and conveniently arranged. The idea that other applications might also contribute to an equalising of opportunities is based upon implausible speculation. Genes that regulate muscle growth, the production of blood vessels or the experience of pain are not digital switches with 'equal output' when turned on.

We can certainly reflect upon the 'ideal' of the genetically modified athlete. We can also question how elite sport has become what it is today and why it is that elite athletes are willing to experiment with highly dangerous means to enhance their performance. Analyses of the present and past are also helpful for understanding the future. In fact, today's science may even learn from science fiction of the past.

\section{The search for 'Perpetual-Motion-Food'}

There are several ways to speculate about possible scenarios and to imagine the unknown. Swierstra ${ }^{27}$ argues that current developments within genomics (a progression from monogenetic to multi-factorial explanations) give rise to new lifeethical issues that cannot be dealt with just by referring to rule-ethical concerns. Artistic images and narratives could very well feed conceptions of our future and how we want to live. The consideration of genetic doping could be enriched by a broad range of narratives that deal with the enhancement of the athlete of the future. Without pretending to deal with this extensively here, I will simply give an example, and draw some interesting parallels with discussions more than a century ago about the promises and dangers attached to the popularisation of cycling.

Around 1900, all kinds of promises were circulating concerning the rising popularity of the bicycle. At the time, there were two opposing theories of human potential. A static view of athletic potential dominated, the idea that fixed laws of nature primarily determined human limits. At the same time a new doctrine of expanding biological limits was emerging. This new doctrine stimulated the projection of fantasies, eugenic discourse and polarised between fears of transgressing human nature and idealistic projections of romantic ideals of taking away human suffering, aging and other limits attached to human existence.

In the year 1900, in Philosophie des Fahrrads, Bertz ${ }^{28}$ wrote about the bicycle as a new technology that would entirely change concepts of time and space and would radically push the limits of human capacities. It would have positive effects on humanity in general, make the human race more fit and would limit any unproductive empathy for human weakness. There were some medical worries concerning the use of the bike (such as scoliosis), but these could in no way diminish all the great things it would do for humanity. This book seems rather quaint now, but the similarities to present-day - in particular transhumanist - rhetoric on gene technology are remarkable. Of course this does not imply that gene technology will become as much a part of everyday life as the bicycle is today (although some like to defend the idea 
that it will). Although Bertz's book clearly reflects the socio-cultural context in which it was written (the paradigm of social Darwinism in particular), it does illustrate the historical continuity of the human urge to fantasise about the transgression of human limits.

An even better example of the role the bicycle played in feeding the fantasies of limitless progress is the science fiction novel Le Surmâle (Supermale), written in 1902 by Alfred Jarry, ${ }^{29}$ an eccentric French playwright. The novel is about an indefatigable Indian who is, breaks records both as a sexual and athletic 'machine'. Jarry, a passionate cyclist himself, was fascinated by the bicycle as modern technology. He described the bicycle as an 'external skeleton which allowed mankind to outstrip the processes of biological evolution'. The novel, which is set two decades into the future, is about the absence of limits to human capacities, in particular with regard to athletic and sexual performance. Part of the novel (probably one of the first that refers to something like doping) is about a 10,000 mile race between a six-man cycling team and a locomotive. The sponsor is a pharmaceutical entrepreneur promoting 'Perpetual-Motion-Food', which is supposed to make the cyclists perform like superhumans. Notwithstanding its surreal character, the book is more or less prophetic. It has some foresight, especially, concerning the connections and alliances between athletic performance, commercial exploitation and the crucial role of the pharmaceutical industry.

General fears of the dehumanising effects of technology are symbolised by the race against the train. At the same time the book is pervaded with optimism about the merging of human bodies with machines and pharmaceuticals. Anyone who has followed professional cycling in the past decade (including all the doping scandals) will acknowledge the richness of this visionary novel. The immense pressures of commerce, for example, are ironically illustrated when one of the riders dies during the race, but stays in his seat while the other riders continue the race on their multirider bike.

Of course, a novel does not solve any concrete problem with regard to the prospect of genetic enhancement, nor can it be read as a prediction of the future. Jarry did however offer an artistic scenario that gives an understanding of the mentality, fears, hopes and the potential dangers that arise from the alliance between medical, athletic and commercial ambitions. Such stories 'invite the reader to imagine and consider ways in which genetic testing might change our world, ideas, values and ideals. ${ }^{30}$ Both utopian and dystopian scenarios often accompany new introductions of technology. The unknown always generates images of both hype and horror. Artistic scenarios are very useful to fill some of the gaps between the ideals and the fears that are projected onto new technology. When speculating about the future, it is sometimes useful to look back and see what is really new and what is not.

\footnotetext{
${ }^{1}$ Faculty of Human Movement Sciences, Vrije Universiteit Amsterdam; i.m.van.hilvoorde@vu.nl

${ }^{2}$ Cf. C. Shilling. 2012. The Body and Social Theory. London and New York, Sage Publications Ltd.
} 
${ }^{3}$ B.D Jordan et al. Apolipoprotein E epsilon4 associated with chronic traumatic brain injury in boxing. JAMA 1997; 278: 136-140.

${ }^{4}$ J. Savulescu. 2005. Compulsory genetic testing for APOE Epsilon 4 and boxing. In Genetic

Technology and sport. Ethical questions. C. Tamburrini and T. Tännsjö (eds.). London and New York, Routledge: 136-146.

${ }^{5}$ B.J. Maron. How should we screen competitive athletes for cardiovascular disease? Eur Heart J 2005; 26: 428-430.

${ }^{6}$ D. Corrado et al. Cardiovascular pre-participation screening of young competitive athletes for prevention of sudden death: proposal for a common European protocol. Eur Heart J 2005; 26: 516-524.

${ }^{7}$ B. Wolfarth. Genetische Polymorphismen bei hochtrainierten Ausdauerathleten - die GenathleteStudie. Deutsche Zeitschrift für Sportmedizin 2002; 53 (12): 338-344.

${ }^{8}$ C. Dennis. Rugby team converts to give gene tests a try. Nature 2005; 434, 260 (17 March 2005); doi:10.1038/434260a

${ }^{9} \mathrm{~T}$. Rankinen et al. The human gene map for performance and health-related fitness phenotypes. Med. Sci. Sports Exerc 2001; 33 (6): 855-867.

${ }^{10}$ M. Schuelke et al. Myostyatin Mutation Associated with Gross Muscle Hypertrophy in a Child. The New England Journal of Medicine 2004; 350: 2682-2688.

${ }^{11}$ I. Van Hilvoorde. 2005. Sport and genetics: Moral and educational considerations regarding 'athletic predestination'. In Genetic Technology and Sport. Ethical Questions. C. Tamburrini and T. Tännsjö (eds.). London-New York, Routledge: 91-103.

${ }^{12}$ Cycling News, 24 December 2006.

http://autobus.cyclingnews.com/news.php?id=news/2006/dec06/dec24news (accessed 26 October 2012).

${ }^{13}$ S. Teetzel. Respecting Privacy in Detecting Illegitimate enhancements in athletes. Sport, Ethics and Philosophy 2007; 1 (2): 159-170.

${ }^{14}$ I. van Hilvoorde. 2010. Mandatory DNA testing in cycling; The role of genetic science in constructing the credible performance. InPhilosophic reflections in sport: a collection of essays. Milan Hosta, ed. Ljubljana: International Institute for Sustainable Development, Policy, and Diplomacy in Sport: $42-48$.

${ }^{15}$ M. A. Rothstein. 1997. Genetic Secrets. Protecting Privacy and Confidentiality in the Genetic Era. New Haven/London: Yale University Press.

${ }^{16}$ I. van Hilvoorde, 2010. Mandatory DNA testing in cycling; The role of genetic science in constructing the credible performance. In Philosophic reflections in sport: a collection of essays. M. Hosta,,ed. Ljubljana: International Institute for Sustainable Development, Policy, and Diplomacy in Sport: $42-48$.

${ }^{17}$ D.C. Malloy and D.H. Zakus. Ethics of Drug Testing in Sport - An Invasion of Privacy Justified? Sport, Educations and Society 2002; 7 (2): 203-218.

${ }^{18}$ Wada. 2003. The world Anti-Doping Code. Lausanne: World Anti-Doping Agency.

${ }^{19}$ See for example the New York Times: http://www.nytimes.com/2007/06/03/sports/playmagazine/0603play-hot.html?pagewanted=all\&_r=0

${ }^{20}$ N. Bostrom, In defense of posthuman dignity. Bioethics 2005; 19: 202-214.

${ }^{21}$ T. Koch, Enhancing who? Enhancing what? Ethics, bioethics, and transhumanism. J Med Philos; 2010; 35 (6): 685-699.

${ }^{22}$ A. Rabinbach. 1990. The Human Motor: Energy, Fatigue, and the origins of Modernity. New York: Basic Books.

${ }^{23}$ E. Fox Keller. 2000. The century of the gene. Cambridge, MA: Harvard University Press.

${ }^{24}$ A. Sandberg. 2001. Morphological Freedom -- Why We not just Want it, but Need it (retrieved from: http://www.nada.kth.se/ asa/Texts/MorphologicalFreedom.htm)

${ }^{25}$ I. van Hilvoorde, R. Vos, \& G. De Wert. Flopping, Klapping and Gene Doping: Dichotomies Between 'Natural' and 'Artificial' in Elite Sport. Social Studies of Science 2007; 37: 173-200.

${ }^{26}$ Boerwinkel et al., Reframing and Articulating Socio-scientific Classroom Discourses on Genetic Testing from an STS Perspective. Science \& Education 2012; http://rd.springer.com/staticcontent/0.5284/pdf/104/art\%253A10.1007\%252Fs11191-012-9528-7.pdf?token=1347996470252-622b755c745ac6fee5083bb0e7017ea8402f09ed7b0cec9ba97b8694b650477c99709a2dcb4bb294e0b02f 
a6724f16e07200eb6907b6a030ba2d7f9748743d3a\&doi=10.1007/s11191-012-9528-

$7 \&$ content Type $=$ article.

${ }^{27}$ T. Swierstra. 2004. Van rechtvaardigheid naar het goede leven: genetica en genomics in de dagbladen. In De genetische ontrafeling van veel voorkomende aandoeningen. H.J.Leschot en D.L.Willems (eds.). Maarsen, Elsevier Gezondheidszorg, Maarsen: 103-124.

${ }^{28}$ E. Bertz, 1997 [1900]. Philosophie des Fahrrads. Paderborn: Snayder Verlag.

${ }^{29}$ A. Jarry. 1970 [1902]. Superman. Amsterdam: Meulenhoff.

${ }^{30}$ Boerwinkel et al., op. cit. note 22, pp. 17. 